\title{
Biodiversity, host specificity, and dominance by eusocial species among sponge-dwelling alpheid shrimp on the Belize Barrier Reef
}

Kenneth S. Macdonald III

Virginia Institute of Marine Science

Ruben Rios

Virginia Institute of Marine Science

J. Emmett Duffy

Virginia Institute of Marine Science

Follow this and additional works at: https://scholarworks.wm.edu/vimsarticles

Part of the Ecology and Evolutionary Biology Commons, and the Marine Biology Commons

\section{Recommended Citation}

Macdonald, Kenneth S. III; Rios, Ruben; and Duffy, J. Emmett, Biodiversity, host specificity, and dominance by eusocial species among sponge-dwelling alpheid shrimp on the Belize Barrier Reef (2006). Diversity and Distributions, 12(2), 165-178.

DOI: $10.1111 /$ j.1366-9516.2005.00213.x

This Article is brought to you for free and open access by the Virginia Institute of Marine Science at W\&M ScholarWorks. It has been accepted for inclusion in VIMS Articles by an authorized administrator of W\&M ScholarWorks. For more information, please contact scholarworks@wm.edu. 


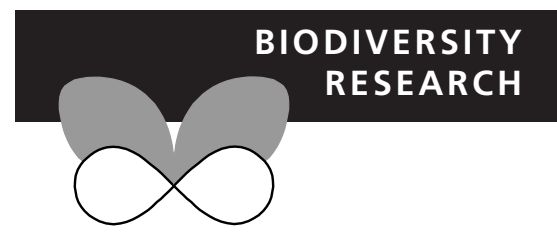

\title{
Biodiversity, host specificity, and dominance by eusocial species among sponge-dwelling alpheid shrimp on the Belize Barrier Reef
}

\author{
Kenneth S. Macdonald III, Ruben Ríos and J. Emmett Duffy
}

School of Marine Science and Virginia Institute of Marine Science, The College of William and Mary, Gloucester Point, VA 23062-1346, USA
${ }^{*}$ Corresponding author. Kenneth Macdonald, School of Marine Science and Virginia Institute of Marine Science, The College of William and Mary, Gloucester Point, VA 23062-1346, USA. Tel.: 804 684-7883; Fax: 804 684-7293;

E-mail: tripp@amnh.org

\begin{abstract}
Alpheid shrimp represent an abundant and diverse, but poorly characterized, component of the cryptic biodiversity of coral reefs worldwide. Sponge-inhabiting alpheids provide a promising model system for exploring patterns of cryptic reef biodiversity because their habitats (hosts) are discrete and qualitatively distinct units. We tabulated data from 14 years of collections at Carrie Bow Cay, Belize to quantify patterns of diversity, host specificity, and dominance among spongedwelling shrimp (Synalpheus), with special attention to eusocial species. From $>600$ sampled sponges of 17 species, we recognized at least 36 Synalpheus shrimp species. Of these, 15 (42\%) were new to science. Species accumulation curves suggest that we have sampled most of the Synalpheus diversity at Carrie Bow Cay. Diversity of sponge-dwelling Synalpheus was slightly higher in shallow water, probably because of greater habitat diversity, than in deep water. Host specificity was surprisingly high, with $>50 \%$ of all shrimp species found in only a single sponge species each, although some shrimp species used as many as six hosts. Cohabitation of individual sponges by multiple shrimp species was rarer than expected by chance, supporting previous distributional and behavioural evidence that competition for hosts is strong and moulds patterns of host association. The fauna of most well-sampled sponge species was dominated, both in numbers of individuals and in frequency of occurrence, by eusocial species. Eusocial shrimp species also inhabited a significantly greater number of sponge species than did non-social shrimp. Consequently, $>65 \%$ of shrimp in our quantitative samples belonged to the four eusocial species, and on a per-species basis, eusocial species were 17 times as abundant as non-social species. Our data suggest that the highly diverse sponge-dwelling shrimp assemblage of the Belize Barrier Reef is structured by competition, and that eusociality has allowed a small number of species to dominate the sponge resource.
\end{abstract}

\section{Keywords}

Competition, coral reef, host range, Porifera, sociality, species accumulation curve, symbiosis.

\section{INTRODUCTION}

Coral reefs are among the most highly diverse marine ecosystems (Kohn, 1997; Ormond \& Roberts, 1997; Reaka-Kudla, 1997). While a great deal of this diversity is obvious to the casual observer, much of it is invisible within the reef framework, consisting of a substantial invertebrate cryptofaunal community (Hutchings, 1983; Kensley, 1998). This community is poorly characterized and generally underrepresented in studies of coral reef biodiversity due to logistical difficulties in sampling, a dearth of systematic knowledge for many cryptic taxa, and the high frequency of closely related, sympatric species (Kohn, 1968; Choat \& Bellwood, 1992; Knowlton \& Jackson, 1994; Duffy, 1996c; Ríos, 2003). A dominant component of this poorly studied cryptofauna is the snapping shrimp genus Synalpheus Bate, 1888 (Felder \& Chaney, 1979; Reed et al., 1982; Snelgrove \& Lewis, 1989). Synalpheus is one of the most diverse and abundant tropical crustacean genera, with over 130 known species worldwide (Banner \& Banner, 1975; Dardeau, 1984; Chace, 1988). In the Caribbean, a majority of the species (Dardeau, 1984; Ríos, 2003) are members of the 'gambarelloides group' of species (Coutière, 1908, 1909), an informal but well-supported (Duffy et al., 2000; 
Morrison et al., 2004) clade of obligate sponge-dwellers. Although all gambarelloides-group species inhabit sponges, they vary considerably in body size (ranging from $<3 \mathrm{~mm}$ to $>30 \mathrm{~mm}$ in length), larval development mode (Dobkin, 1965, 1969), and social structure, ranging from pair-forming species to eusocial (Duffy, 1996a) species forming colonies of $>300$ individuals.

The high diversity of sponge-dwelling Synalpheus has made these shrimp a model system for study of host-mediated evolution (Duffy, 1996b,c) and sociobiology (e.g. Duffy, 1996a, 2003; Duffy et al., 2000). Sponge-dwelling shrimp might also serve as a general model for exploring diversity patterns in other cryptic reef taxa that are difficult to sample quantitatively because of their inaccessible and heterogeneous habitats. Synalpheus shrimp live in discrete, qualitatively distinct habitat units (sponges) that can be quantified, but otherwise share many ecological characteristics with other cryptic invertebrates, such as small size, sedentariness, low population density, and patchy distribution. Comparative approaches to understanding evolution, sociobiology, and patterns of biodiversity of sponge-dwelling shrimp all require accurate information on host-use patterns. Here we exploit a newly revised taxonomy (Ríos, 2003) and an extensive series of collections from Carrie Bow Cay (CBC), Belize to explore patterns of diversity and host association in Synalpheus. The island of CBC is part of the Belize barrier reef complex, the longest continuous reef in the Caribbean (Adey, 1977; Rützler \& MacIntyre, 1982), and a region known for its high diversity of coral reef fauna. During a 14-year period, sponges and associated shrimp were sampled in the vicinity of CBC for the purpose of systematic, evolutionary, and behavioural research (e.g. Duffy, 1992, 1996a,c, 2003). These collections provide the opportunity to sketch a quantitative picture of the biodiversity and ecological distribution of one of the most species-rich, but poorly known, components of cryptic coral-reef biodiversity, and to assess indirectly the role of sociality in ecological dominance of the spongedwelling niche.

In addition to characterizing patterns of diversity and distribution of sponge-dwelling shrimp, we used the data from our collections to explore a series of hypotheses about the role of sociality in shrimp distribution and dominance. First, does host range (number of host species used) differ between eusocial and non-social shrimp species? Second, are eusocial shrimp more abundant than non-social shrimp? Finally, is there evidence for competitive exclusion among shrimp species?

\section{METHODS}

\section{Study sites}

Sponges were collected in the vicinity of the Smithsonian Institution's research station at $\mathrm{CBC}$, Belize $\left(16^{\circ} 48^{\prime} \mathrm{N}, 88^{\circ} 05^{\prime} \mathrm{W}\right.$; Fig. 1). The fore reef adjacent to $\mathrm{CBC}$ and those reefs directly to its south share many structural similarities (Rützler \& MacIntyre, 1982). East (seaward) from the reef crest the reef deepens into the spur and groove zone $(3-10 \mathrm{~m})$, characterized during the period of our sampling by high coral spurs, mainly Agaricia tenuifolia Dana, 1846 and Millepora complanata Lamarck, 1816, separated by deep sand grooves. Further eastward, the reef deepens into the inner reef slope, characterized by a variety of coral species, including Montastrea annularis Ellis and Solander, 1786, Porites asteroides Lamarck, 1816, and A. tenuifolia, as well as large sponges, gorgonians, and macroalgae. The reef typically descends into a deep (c. $25 \mathrm{~m}$ ) sand trough, beyond which rises the outer ridge, which may reach within $15 \mathrm{~m}$ of the surface, but averages $c .20 \mathrm{~m}$. Seaward of the ridge, the reef drops steeply to several hundred metres, demarcating the edge of the continental shelf. In some areas, the inner and outer reef slopes merge, with no sand trough or discernable 'ridge' before the drop-off. The outer ridge has a similar fauna to the inner slope, as well as large Agaricia agaricites Linnaeus, 1758, Diplora labyrinthiformis Linnaeus, 1758, and Madracis mirabilis Duchassaing and Michelotti, 1860 (Rützler \& Macintyre, 1982).

To the west, between the barrier reef and the mainland, is a shallow lagoon ranging in depth to $20 \mathrm{~m}$, populated by numerous patch reefs and mangrove islands. Approximately $2 \mathrm{~km}$ to the north-west of CBC is Twin Cays, a mangrove island surrounded by turtle grass (Thalassia testudinum Banks and Solander ex König, 1805) beds. South-west of CBC (3-4 km) are a number of patch reefs, the 'Sand Bores' (also known as 'Pinnacles'), surrounded by deep water, and often exposed to relatively high wave energy, with the seaward side characterized by Porites porites Pallas, 1766, Porites furcata Lamarck, 1816, A. agaricites, Acropora palmata Lamarck, 1816, and substantial rubble. Macroalgae and gorgonians are common on these patch reefs, but sponges are mostly cryptic.

\section{Collections}

Sponges were collected using SCUBA $(>20 \mathrm{~m})$ and snorkelling $(<5 \mathrm{~m})$ primarily from four areas: the outer reef ridge off $\mathrm{CBC}$ and reefs immediately to its south; the spur and groove zone off CBC and immediately south; Thalassia beds surrounding Twin Cays; and shallow coral rubble from the Sand Bores. Collections were made in December 1990, March 1993, August 1994, June and July 1995, June 1996, December 1998, December 1999, April and May 2001, June 2002, April 2003, and March 2004.

On the reef slope, macroscopic sponges, and cryptic sponges attached to dead coral rubble, were collected using SCUBA. During the initial collections at a given site, scuba divers swam along the reef, collecting one or a few samples of most species of visible sponges. Collected sponges were transported to the field station at $\mathrm{CBC}$, and retained in flowing seawater until they could be processed. Sponges were subsequently dissected, and all macrofauna was removed from the internal canals of the sponge. Alpheid shrimps were sorted by species, usually counted and sexed, then preserved in c. $10 \%$ formalin in seawater, $70 \% \mathrm{EtOH}$, or 95\% EtOH. Representative samples of each sponge were preserved in $70 \% \mathrm{EtOH}$ for later identification. Until 2001, sponges were placed together in large mesh bags as they were collected, and were stored together in the seawater tanks. Starting in 2001, sponges were placed in individual small mesh bags as they were collected. Initially, a wide variety of sponges were sampled to ascertain which hosted shrimp. As sampling continued over the years, collections focused primarily on the specific sponges in 
Figure 1 Map showing the vicinity of Carrie Bow Cay, Belize. X's mark sampling areas at Carrie Bow, Twin Cays and the Sand Bores. Courtesy of Caribbean Reef Ecosystems Program, Smithsonian Institution (original prepared by Molly K. Ryan).

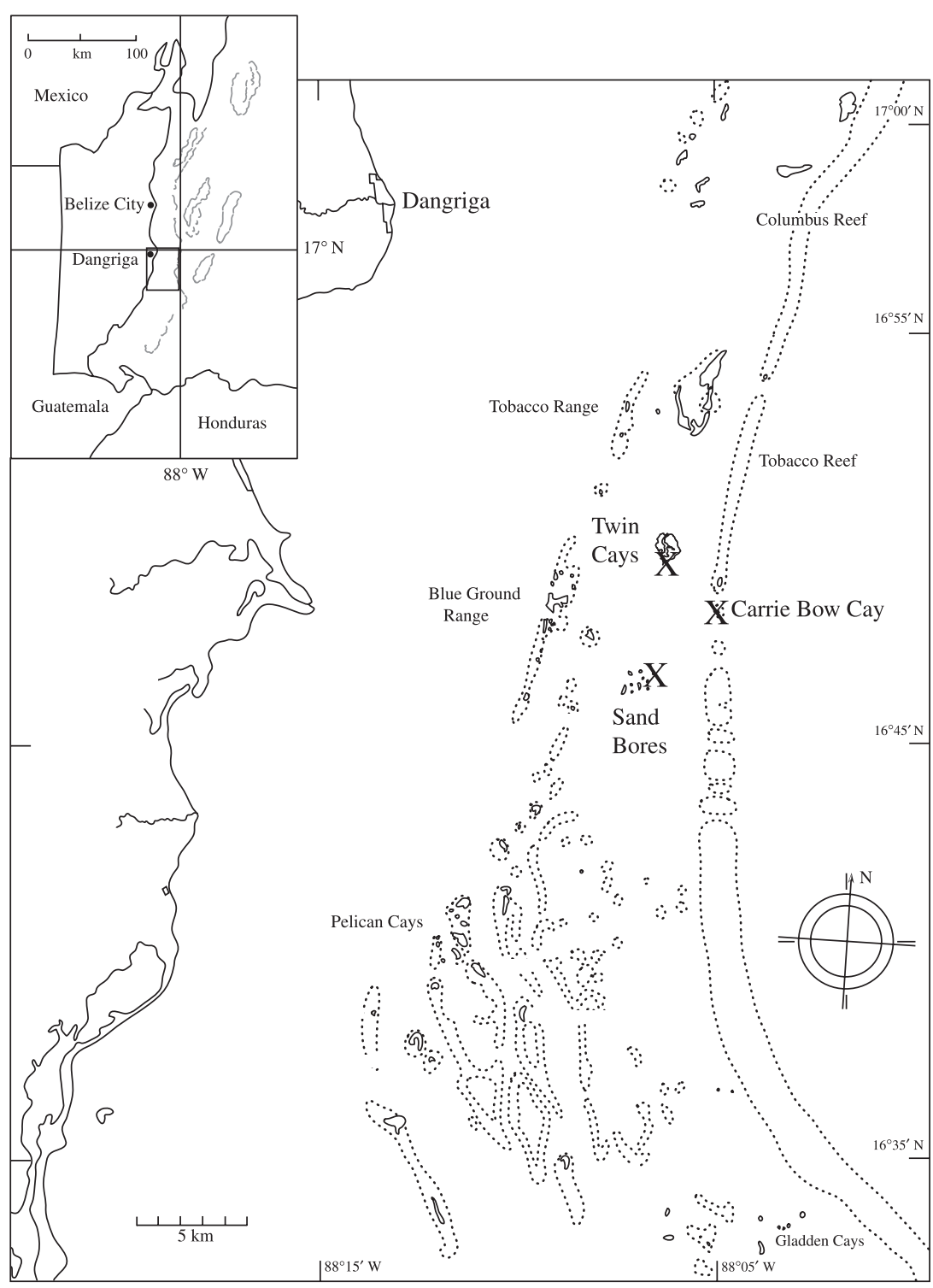

identified to species using keys found in Chace (1972), Dardeau (1984) and Ríos (2003).

\section{Taxonomy}

Many of the shrimp species we collected have not yet been formally described in the peer-reviewed literature (see Results), although they have been described in a dissertation (Ríos, 2003), and a formal taxonomic revision of sponge-dwelling Synalpheus based on that work is currently in preparation (R. Ríos and J. E. Duffy, in preparation). Briefly, our species designations are based on many years of field study of the colour, host associations, body size, and social structure of living shrimp, supplemented by careful microscopic examination of morphology (Duffy, 1996d, 1998; Ríos \& Duffy, 1999; Ríos, 2003) and, for many taxa, supporting molecular data (Duffy, 1996c; Duffy et al., 2000; Morrison et al., 2004). All of the putative species taxa listed in this paper are based on at least three heterosexual pairs of specimens from different individual sponges sharing some combination of 
distinctive colour, morphological characters, molecular characters, and host associations. Our tentative species designations have often been further corroborated by assortative mating among morphotypes, which is deducible from the (non-eusocial) alpheid habit of living in heterosexual pairs.

\section{Analyses}

To determine whether we have adequately sampled the Synalpheus diversity in the $\mathrm{CBC}$ area, we calculated mean estimates (and 95\% CIs) of true diversity using the Michaelis-Menten (Michaelis \& Menten, 1913) logistic curve-fitting function in the program newvs (M. E. Siddall, 1999) with 100 randomized resamplings. Estimates of the asymptote and the curve shape function were used to create an average species accumulation curve with 95\% CIs. Three non-curve-fitting measures were also used to estimate true species richness: the Burnham and Overton (1978) second order jackknife, Chao's (1987) Chao2 measure, and the Smith and van Belle (1984) bootstrap.

All analyses of host association considered only those shrimpsponge species combinations represented by at least three separate records; this was intended to minimize any potential bias from aberrant specimens or 'stray' shrimp that may have moved among sponges during rubble collections. The consistency and specificity of host associations (see Results) suggest that such potential artefacts did not appreciably influence the results. To test the hypothesis that host range (number of host species used) differed between eusocial and non-social shrimp species, we tallied the number of host species used by each shrimp species, and calculated the mean host range for eusocial and non-eusocial species. Using an Excel resampling macro (Blank et al., 2001), we then reshuffled host ranges (without replacement) among all gambarelloides-group species, and recalculated the average host ranges and the difference in host range between eusocial and non-social species. This reshuffling procedure was repeated 10,000 times, after which we calculated the expected mean $( \pm 95 \% \mathrm{CI})$ difference in host range between eusocial and noneusocial shrimp under the null hypothesis of random variation in host range among eusocial and non-social species. The 95\% CIs were defined as the upper and lower bounds within which 95\% of reshuffled values fell. If the observed difference between eusocial and non-eusocial shrimp host range was greater than the upper 95\% CI, we considered the difference to be statistically significant. We define host range as the number of sponge species in which a shrimp was found three or more times. Because of the possibility of shrimp moving among sponges after collection, we consider single instances of sponge habitation unreliable, especially for those sponges with large sample sizes, and we decided to discount them when determining host specificity.

Second, to determine whether shrimp abundance was related to sociality, we compared numbers of individual eusocial and non-eusocial shrimp species in coral rubble samples collected in the Sand Bores. Because the rubble was collected with little knowledge of the associated sponges therein, these rubble samples can be considered haphazard, unbiased samples of the cryptofaunal shrimp assemblage. In contrast, collections from all other sites tended to target specific sponge species. Rubble samples from the Sand Bores were collected on 13 separate days between 1994 and 2004. For this analysis, we considered the collection from a given day $(n=13)$ as a single quantitative sample. These samples contained both sponge-dwelling (gambarelloides-group) and free-living (non-gambarelloides) shrimp. Because total abundance of collected shrimp varied among dates, we expressed abundance of each species as the percentage of that day's total collection. We used a paired-sample $t$-test to test whether the log of summed abundance of eusocial species in the samples differed from the log of summed abundance of non-social species. We also tested whether the average (proportional) abundance of eusocial species differed from the average abundance of non-social species.

To explore the possibility of competitive exclusion among shrimp species, we tested whether different species of shrimp co-occupied individual sponges less frequently than expected by chance. We performed this analysis separately for each of the major host sponge species. To do so, we listed the occurrences of each shrimp species in sampled individuals of that sponge species, tallied observed co-occurrences of shrimp species, then reshuffled the occurrences (without replacement) among individual sponges, and recalculated frequency of co-occurrences. This reshuffling procedure was repeated 10,000 times, after which we calculated the expected median ( $\pm 95 \%$ CI) numbers of co-occurrences of two or more shrimp species under the null hypothesis of random distributions of occurrences among individual sponges. When the observed number of co-occurrences was outside the $95 \%$ CI of the reshuffled data, we considered the difference between observed and expected co-occurrences statistically significant.

\section{RESULTS}

Over the course of 11 collecting trips totalling c. 139 field days and spanning 14 years, at least 36 putative species of Synalpheus shrimp were found inhabiting a total of 17 sponge species ( $N=623$ sampled fauna-bearing sponges) in the vicinity of CBC, Belize (Table 1). Of these 36 Synalpheus species collected, 27 were members of Coutière $(1908,1909)$ gambarelloides species group. The number of Synalpheus shrimp species increased approximately linearly with the first 100 sponge specimens sampled, and approached an asymptote of 36 species after $c$. 250 sponges were sampled (Fig. 2a). All four estimates of species richness were similar or identical to the observed richness: asymptotic curve function $=36$ (Fig. 2a), jackknife $=37$, Chao $2=36$, and bootstrap $=36$. However, our observed accumulation curve fell below the lower $95 \%$ CI of the estimated curve. We found 28 species of Synalpheus shrimp in the deep waters of the reef slope (where collection effort was highest), 32 species at the shallower Sand Bores, 5 at the spur and groove, and 11 in the Thalassia beds. Overall, shrimp diversity was higher in shallow than in deep water (Fig. 2b), probably because of the greater habitat diversity sampled in shallow water, and was still increasing approximately linearly at the end of our collections (Fig. 2b).

The number of shrimp-bearing sponge species also approached an asymptote after c. 250 sponges sampled (Fig. 2c). 
Table 1 Host associations of Synalpheus shrimp species at Carrie Bow Cay, Belize. Entries in main body of text are numbers of sampled sponges that contained a given shrimp species. Shrimp species names in quotes are provisional names of undescribed species and follow Morrison et al. (2000). $\mathrm{H}^{\prime}$ = Shannon-Wiener Index of diversity. 'New species' denoted by asterisk

\begin{tabular}{|c|c|c|c|c|c|c|c|c|c|c|c|c|c|c|c|c|c|c|c|c|}
\hline & 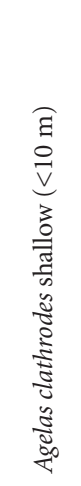 & 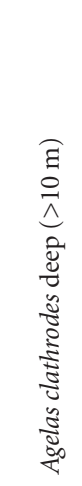 & 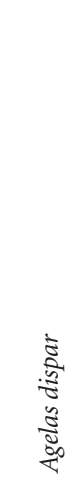 & 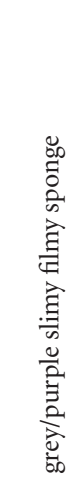 & 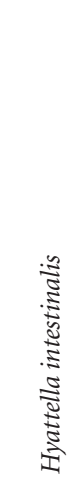 & 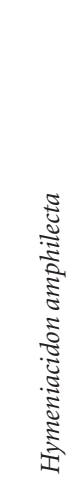 & 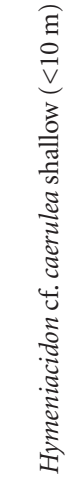 & 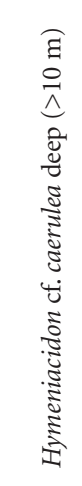 & 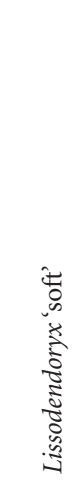 & 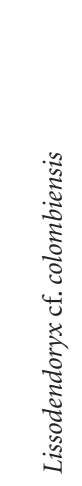 & 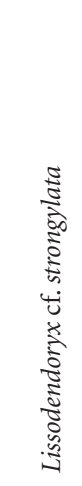 & 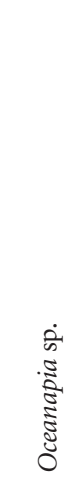 & 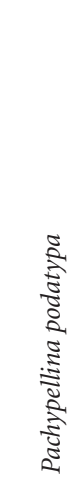 & 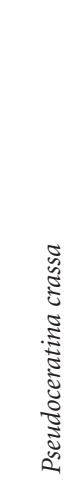 & 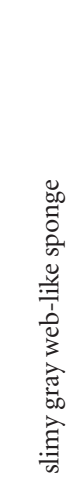 & 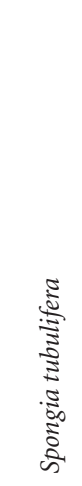 & 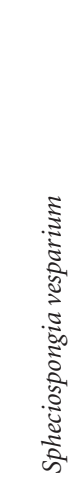 & 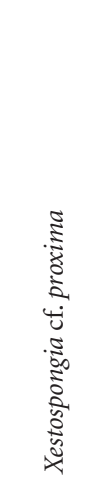 & 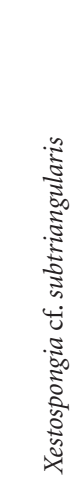 & 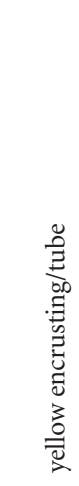 \\
\hline Total \# Individual Sponges Sampled & 21 & 38 & 19 & 4 & 94 & 27 & 31 & 30 & 10 & 18 & 72 & 38 & 20 & 11 & 3 & 1 & 20 & 50 & 108 & 7 \\
\hline \# Sponges sampled from Reef Slope $(>15 \mathrm{~m})$ & 0 & 38 & 9 & 2 & 86 & 19 & 0 & 30 & 8 & 0 & 71 & 35 & 1 & 10 & 1 & 0 & 3 & 37 & 104 & 0 \\
\hline \# Sponges sampled from Spur and Groove $(<10 \mathrm{~m})$ & 8 & 0 & 9 & 0 & 0 & 5 & 0 & 0 & 1 & 0 & 0 & 0 & 0 & 0 & 0 & 0 & 0 & 0 & 0 & 0 \\
\hline \# Sponges sampled from Sand Bores $(<3 \mathrm{~m})$ & 11 & 0 & 0 & 2 & 8 & 3 & 31 & 0 & 1 & 0 & 1 & 3 & 19 & 1 & 2 & 0 & 8 & 13 & 4 & 7 \\
\hline \# Sponges sampled from Grassbeds $(<2 \mathrm{~m})$ & 2 & 0 & 1 & 0 & 0 & 0 & 0 & 0 & 0 & 18 & 0 & 0 & 0 & 0 & 0 & 1 & 9 & 0 & 0 & 0 \\
\hline Total \# inhabitant shrimp species & 4 & 11 & 4 & 1 & 13 & 4 & 10 & 8 & 2 & 7 & 7 & 4 & 5 & 6 & 1 & 1 & 3 & 6 & 6 & 4 \\
\hline $\mathrm{H}^{\prime}$ mean 0 & 0.065 & 0.294 & 0.321 & 0.000 & 0.234 & 0.172 & 0.127 & 0.205 & 0.006 & 0.370 & 0.026 & 0.035 & 0.065 & 0.046 & 0.000 & 0.000 & 0.224 & 0.006 & 0.004 & 0.139 \\
\hline $\mathrm{H}^{\prime}$ stdev 0 & 0.265 & 0.429 & 0.326 & 0.000 & 0.319 & 0.240 & 0.304 & 0.331 & 0.018 & 0.388 & 0.142 & 0.130 & 0.202 & 0.137 & 0.000 & 0.000 & 0.233 & 0.027 & 0.017 & 0.310 \\
\hline gambarelloides & & & & & & & & & & & & & & & & & & & & \\
\hline agelas (ag) & 2 & 14 & 9 & & & & & & & & & & & & & & & & & \\
\hline androsi (an) & & 1 & & & 26 & & & 1 & & & & & & 1 & & & & & & \\
\hline bousfieldi (bs) & & & & & 45 & & & & & & & & & & & & & & & \\
\hline 'bousfieldi A' (bA)* & 5 & 13 & 9 & & & & & & & & & & & & & & & & & \\
\hline brevifrons (bf) & & & & 4 & & & & 1 & & & & & & 1 & & & & & & \\
\hline brooksi (bk) & & & & & & & & & & 15 & & & & & & & 19 & & & \\
\hline 'brooksi complex' (bc)* & & 2 & & & & & 22 & 10 & & & 3 & & & 1 & & & & & 1 & 1 \\
\hline 'brooksi $\mathrm{D}$ ' $(\mathrm{bD})^{\star}$ & & & & & & 12 & & & & & & & & & & & & & & \\
\hline chacei $(\mathrm{ch})^{*}$ & 16 & 16 & 13 & & 32 & 22 & & & & & 65 & 1 & & & & & & 1 & 4 & \\
\hline filidigitus (fi) & & & & & 3 & & & & & & & 33 & 3 & & & & & 44 & 14 & \\
\hline goodei (go) & & & & & 1 & & & & & & & & 11 & & & & & & & \\
\hline heardi (he) & & 3 & & & & & & & & & & & & & & & & & & \\
\hline herricki (hr) & & & & & 1 & 5 & & & & & & & & & & & & & & \\
\hline 'intermediate' (in)* & & & & & 1 & & & & & & & & & & & & & & & 4 \\
\hline 'longicarpus small' $(1 \mathrm{~s})^{*}$ & & & & & & & & & & & & & 4 & & & & & & & \\
\hline mcclendoni (mc) & & 4 & & & & & & & & & & & & & & & & & & \\
\hline 'near chacei' (nc)* & & & & & & & 1 & 2 & & & & & & & & & & & & \\
\hline 'near sanctithomae' (ns)* & & 1 & & & & & & & & & & & & & & & & & & \\
\hline
\end{tabular}


Table 1 Continued

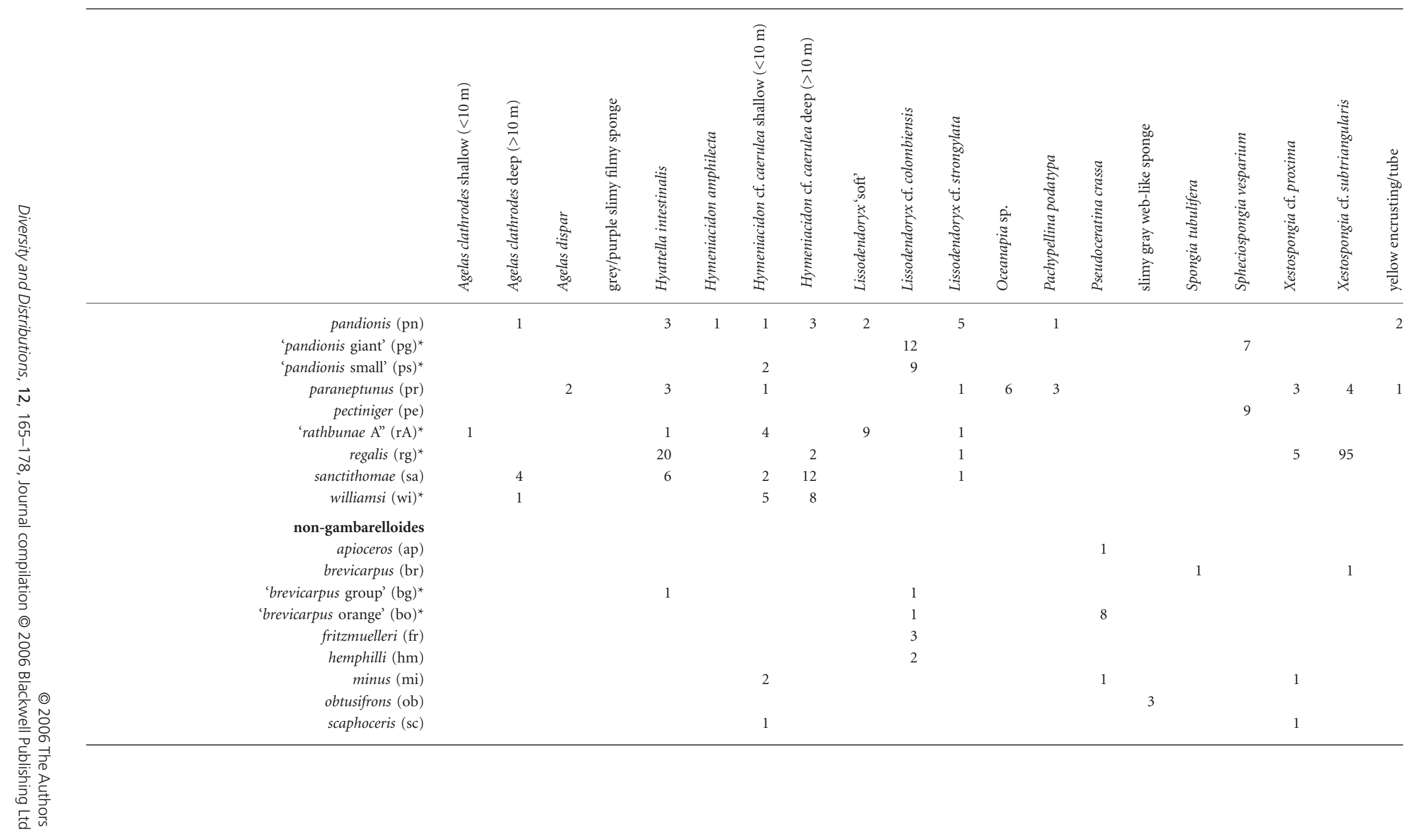


(a)

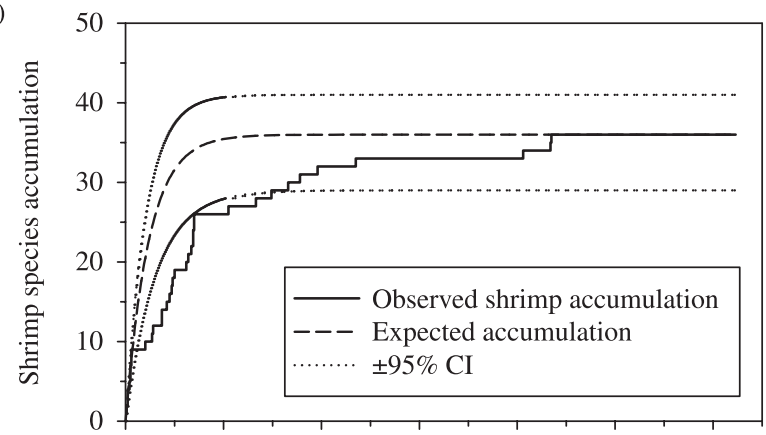

(b)

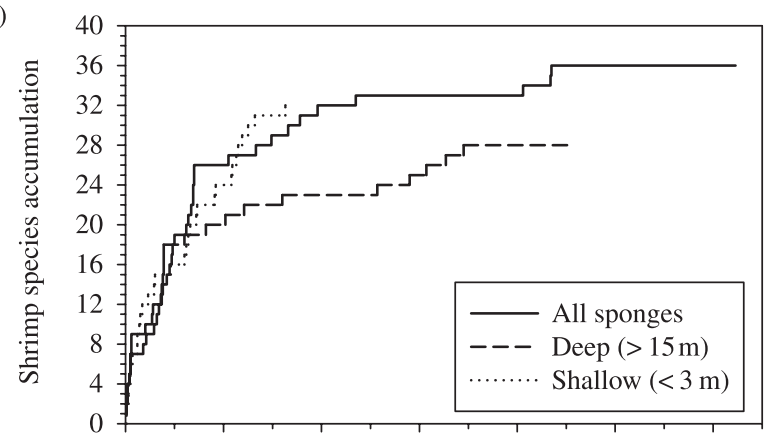

(c)

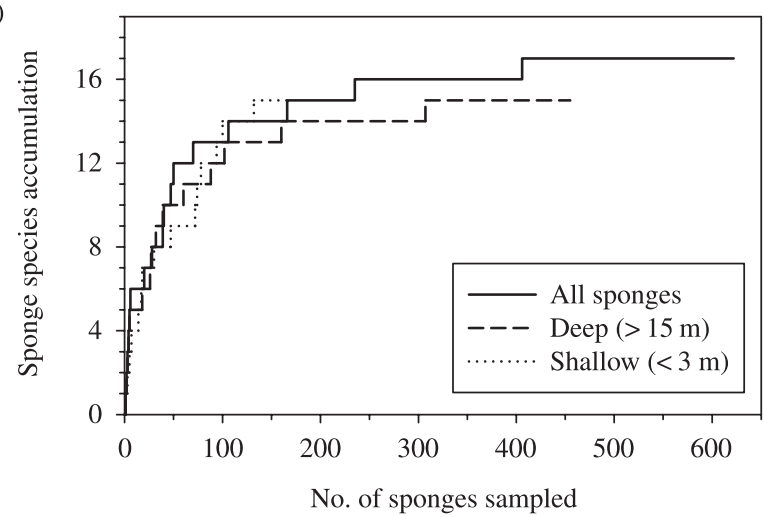

Figure 2 Accumulation of Synalpheus shrimp species as a function of collection effort (number of sponge specimens collected) (a) for all sampled sponges, and (b) separated by depth of collection. (c) Accumulation of sponge species as a function of collection effort. Estimated species richness curve (dashed curve in a) and 95\% CI (dotted curves in a) were calculated using the program newvs (M.E. Siddall, American Museum of Natural History, available on request).

We found 15 species of shrimp-infested sponges on the reef slope, and the same number at the Sand Bores. Four sponge species supported shrimp in the spur-and-groove zone and five in Thalassia beds. Agelas clathrodes Schmidt, 1870 was one of the few sponges found in every habitat sampled. Similarly, Agelas dispar Duchassaing and Michelotti, 1864 was sampled in all habitats except at the Sand Bores. Hyatella intestinalis Lamarck, 1814 was a cryptic sponge, found predominantly on the reef slope in Madracis coral rubble. Hymeniacidon cf. caerulea Pulitzer-Finali, 1986 was found cryptically in coral rubble in the Sand Bores and reef slope. Lissodendoryx colombiensis Zea and van Soest, 1986 and Spheciospongia vesparium Lamarck, 1814 were found (a)
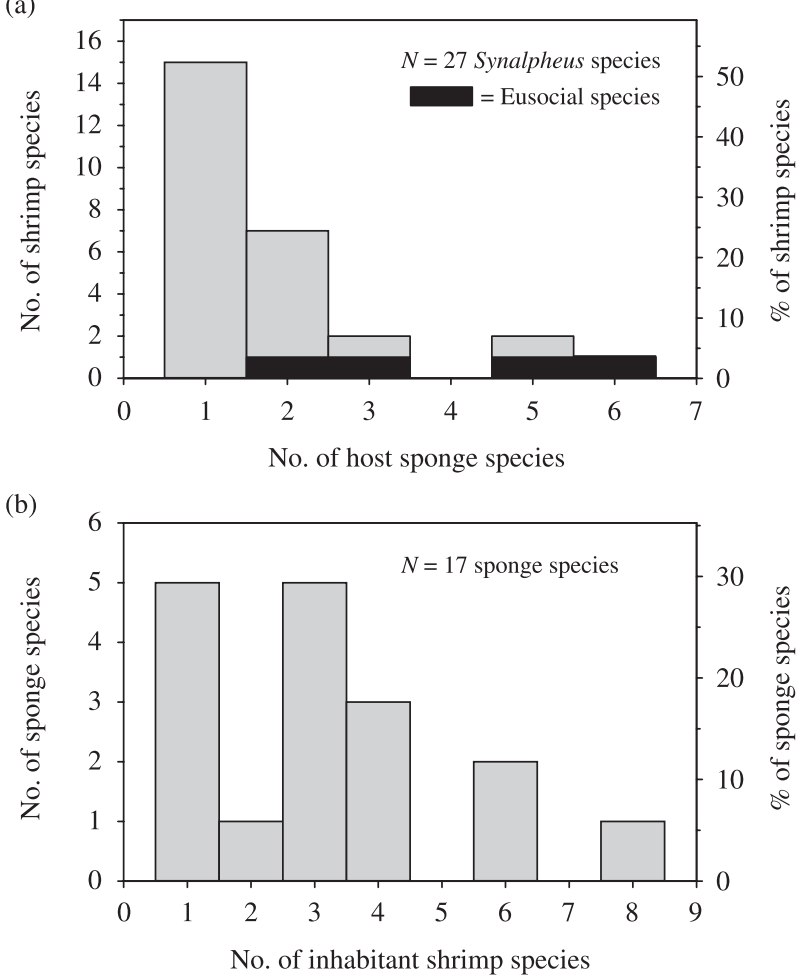

Figure 3 Host specificity in sponge-dwelling Synalpheus shrimp. (a) Frequency distribution of shrimp host range, i.e. number of sponge species occupied by a given shrimp species. (b) Frequency distribution of sponge symbiont diversity, i.e. number of shrimp species harboured by a single sponge species. For each sponge species, only shrimp species found inhabiting three or more individual sponges were included.

primarily in Thalassia beds at Twin Cays. Lissodendoryx cf. strongylata van Soest, 1984, Oceanapia sp., Xestospongia cf. proxima Duchassaing and Micheletti, 1864, and Xestospongia cf. subtriangularis Duchassaing, 1850 were all primarily found in Madracis rubble on the reef slope.

Of the 27 gambarelloides-group Synalpheus species found, at least 13 were identified as new to science. We categorized Synalpheus species described prior to Duffy (1996d; the first species description resulting from the Belize collections) as 'previously known' and species determined to be undescribed prior to our collecting efforts at CBC 'new'. Of the 13 'new species', three have been formally described (Duffy, 1996d, 1998; Ríos \& Duffy, 1999), five were described in a dissertation (Ríos, 2003), and are in preparation for publication, and the remaining five are currently undescribed. Previously known and new species were found at approximately equal rates during collection of the first 50 sponge specimens (not shown); and by the end of our collections, almost exactly half $(48 \%)$ of gambarelloides species collected were new, i.e. previously undescribed (see Duffy, 1996d, 1998; Ríos \& Duffy, 1999; Ríos, 2003).

Host range of Synalpheus shrimp varied from one to six sponge species, with more than $50 \%$ of shrimp species at CBC inhabiting only a single sponge species (Fig. 3a, Table 1). Across 

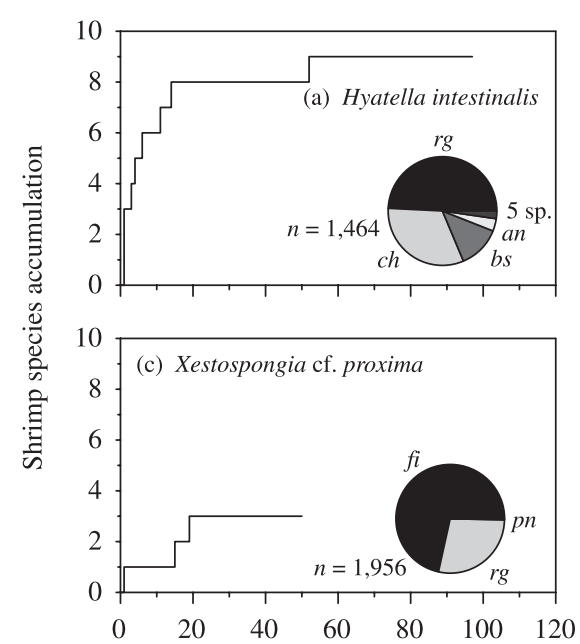

No. of sponges sampled

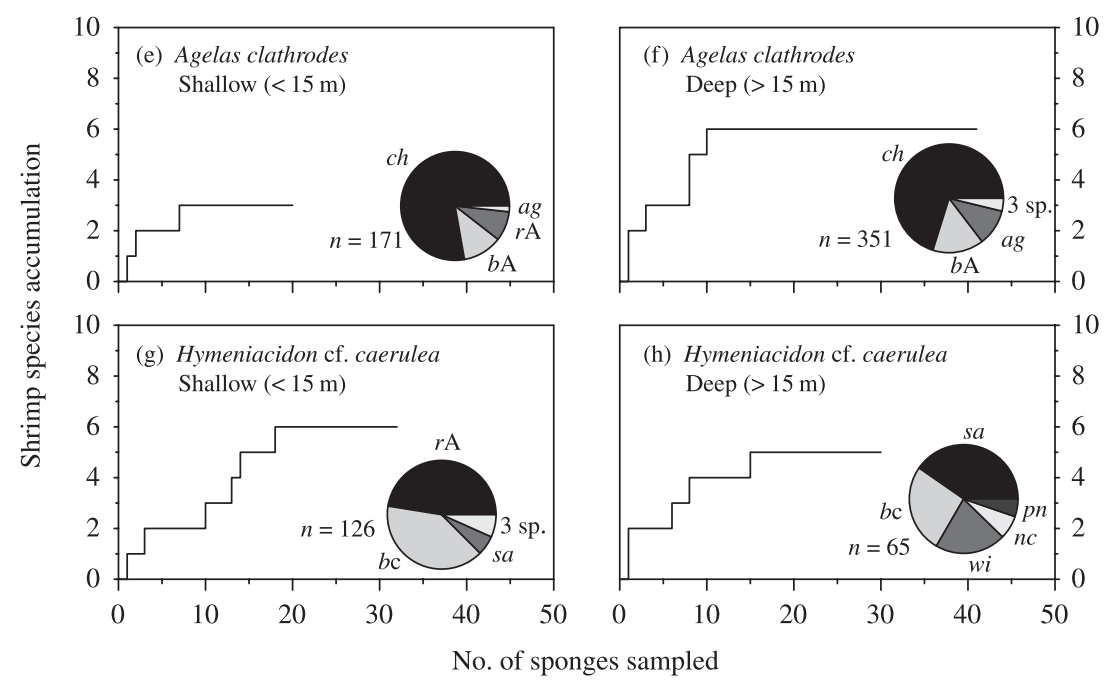

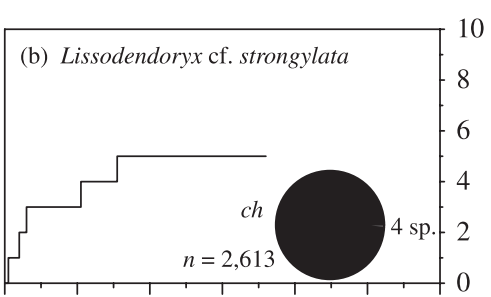

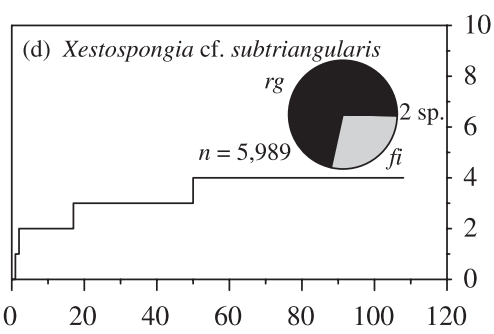

Figure 4 Accumulation of Synalpheus shrimp species as a function of number of individual sponges collected for each sponge species of which 50 or more individuals were sampled. Inset pie charts show proportion of Synalpheus individuals (of total shrimp collected) by species for each sponge species. Shrimp species abbreviations follow those in Table 1. Lower four panels show separate plots by depth for two sponge species sampled at both shallow $(<10 \mathrm{~m})$ and deeper $(>15 \mathrm{~m})$ depths. species, log host range was positively correlated $\left(R^{2}=0.45\right)$ with $\log$ of total numbers of shrimp collected. Host range of eusocial shrimp species averaged $4.0 \pm 0.9$ (mean \pm SE, $N=4$ species), significantly larger $(P<0.05$, as reflected in non-overlapping $95 \%$ bootstrapped CI) than for non-eusocial species (1.5 \pm 0.1 , $N=23$ species). Sponges also differed considerably in the diversity of shrimp they harboured, ranging from one to eight, with modes at one and three species (Fig. 3b).

Shrimp species accumulation curves for each of the six wellsampled sponges, i.e. those represented by at least 50 specimens (Fig. 4), generally followed similar patterns as the overall accumulation curve (Fig. 2a), with shrimp species accumulation rising steeply for the first $c .20$ individual sponges sampled, and reaching an asymptote soon thereafter. These sponge-specific accumulation curves also included only shrimp species that were found in at least three individual sponges. The fauna of most sponges was dominated by one or two shrimp species (inset pie charts, Fig. 4), and in all but one case (H. careulea deep), the most abundant shrimp was one of the four eusocial species Synalpheus regalis Duffy, 1996, Synalpheus chacei Duffy, 1998, Synalpheus filidigitis Armstrong, 1949, or Synalpheus 'rathbunae
A'. Two sponges, $A$. clathrodes and $H$. caerulea, were sampled in relatively large numbers in both shallow $(<5 \mathrm{~m})$ and deep ( $>15 \mathrm{~m}$ ) habitats, allowing comparison of the faunas of conspecific hosts at different depths (Fig. 4e-h). Shrimp assemblages differed with depth in both sponges, with greater Shannon-Wiener species diversity $\left(\mathrm{H}^{\prime}\right)$ in deep samples for both $A$. clathrodes $\left(\mathrm{H}^{\prime}=0.065\right.$ for shallow, 0.429 for deep) and H. caerulea ( 0.127 for shallow, 0.205 for deep).

Despite comprising only 4 of the 27 gambarelloides-group species collected, eusocial shrimp species were far more abundant than either non-social species in the group or free-living shrimp species outside the gambarelloides group (Fig. 5). On average, $68 \pm 8 \%$ (mean \pm SE, $n=4$ species) of all individual shrimp collected from each day's rubble samples belonged to one of the four eusocial shrimp species, whereas only $22 \pm 6 \%$ were non-social gambarelloides species, a significant difference $(t=2.49, P=0.028, N=13$, Fig. 5a). Each eusocial shrimp species made up an average of $17 \pm 2 \%$ (mean \pm SE, $n=4$ species) of all individuals collected, whereas non-social species each comprised, on average, $0.9 \pm 0.2 \%$ of individuals (Fig. 5b). 
(a)

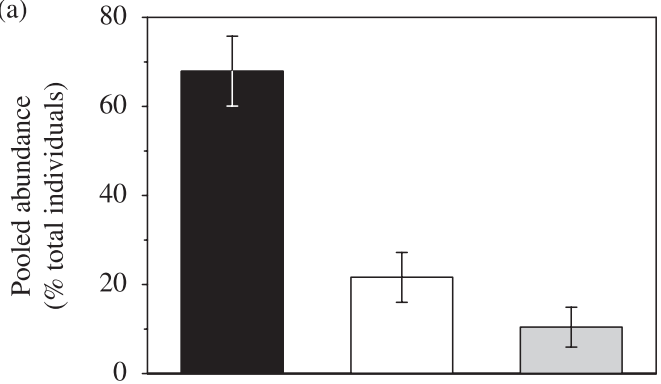

(b)

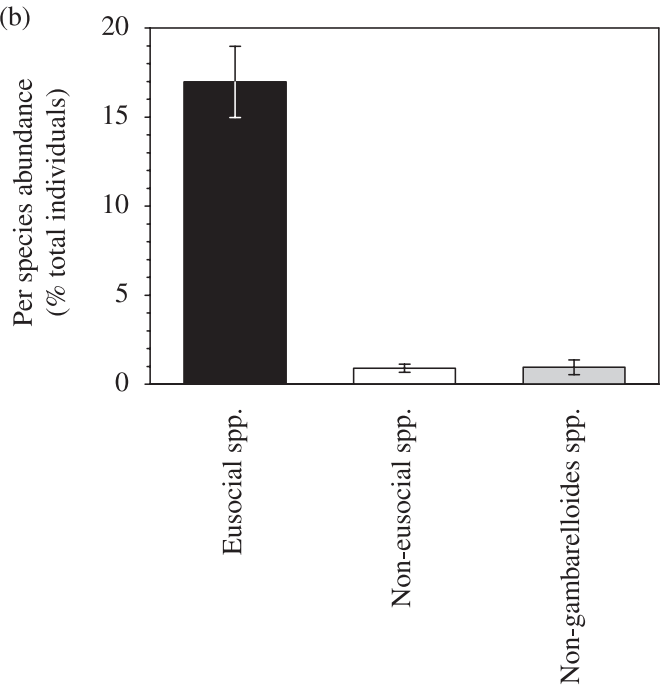

Figure 5 Mean $( \pm$ SE) abundance of eusocial and non-social shrimp in the gambarelloides group, and non-gambarelloides shrimp species, from quantitative rubble samples from the Sand Bores. (a) Pooled proportional abundance of all eusocial or nonsocial shrimp species in each sample. (b) Mean proportional abundance of individual species in each category. $n=4$ species for eusocial species, $n=24$ for non-social species, $n=11$ for non-gambarelloides species.

Five of the six best-sampled sponge species harboured only a single shrimp species significantly more often than expected by chance, whereas multiple species of shrimp cohabited in individual sponges less often than expected by chance (Fig. 6). Finally, the number of cohabiting species within a sponge does not appear to be related to the number of individual shrimp within the sponge (Fig. 7).

\section{DISCUSSION}

Symbiotic associations are a hallmark of high-diversity coral-reef ecosystems. Our data provide one of the most complete quantitative assessments of the diversity and distribution of a group of symbiotic reef invertebrates, albeit focused on only a single genus of symbionts. Thus, an important question in interpreting our data involves the completeness of sampling: have we sampled the Synalpheus diversity at Carrie Bow Cay (CBC) in its entirety? Species accumulation curves suggest that we have come close both overall and in deep water, but despite intensive sampling for over 14 years, shallow-water diversity continues to increase. This underscores the remarkable diversity, much of it still undescribed, of tropical alpheids. The overall accumulation curve for Synalpheus species (Fig. 2) does reach an asymptote, as do the curves for the wellsampled sponge species (Fig. 4). Most of the poorly sampled sponges ( 5 species with 10 or fewer individual sponges collected) harbour few shrimp species and seem unlikely to add much to overall diversity. On the other hand, Synalpheus biodiversity at CBC may well increase with further taxonomic study of the undescribed species. Several of the putative shrimp species taxa encountered in this study are probably cryptic species complexes (e.g. S. 'brooksi complex'), suggesting that an estimate of Synalpheus diversity could increase even in the absence of additional sampling. Over the last 10 years alone, the increase in known Synalpheus diversity at CBC has been substantial, with 15 putative new species recognized (Duffy, 1996d, 1998; Ríos \& Duffy, 1999; Ríos, 2003), compared with 21 previously known species. There has been too little geographical sampling to determine how many of the species we found are endemic to the $\mathrm{CBC}$ region. But it is likely, given that our collections at $\mathrm{CBC}$ have nearly doubled the number of previously known West Atlantic gambarelloides-group species, that intensive study of other Caribbean sites would add considerably to the known diversity of alpheids.

Our results confirm that the assemblage of sponge-dwelling alpheids on the Belize Barrier Reef is highly diverse and highly structured in terms of host specificity. Of the Synalpheus species found in our study, a remarkable $56 \%$ were found in only a single host sponge species. Moreover, the sponges themselves are highly specific in their habitat requirements. Many of the sponges harbouring shrimp on the deep reef are found almost exclusively among dead or basal branches of the coral M. mirabilis. These include the most commonly inhabited sponge species, H. intestinalis, both Xestospongia spp., and L. strongylata, which, coincidentally, are also the primary hosts of most of the eusocial shrimp found in Belize. In addition to this strong host specificity, two lines of evidence support previous arguments (Duffy, 1992, 1996c,d, 2003) for strong inter- and intraspecific competition for host resources among these symbiotic shrimp. First, cohabitation of individual sponges by multiple shrimp species was rarer than expected by chance (Fig. 6). Second, our collections suggest that sponge habitat is 'saturated' in that there is little if any open resource available: in over 14 years of collecting more than 600 sponges, we rarely found an individual sponge that was empty of shrimp among the 17 Synalpheus-supporting species. Thus, despite the apparently restricted dispersal ability of spongedwelling alpheids (e.g. Dobkin, 1965), we found no evidence of recruitment limitation. Competitive exclusion of congeners could also help explain the difference between the observed species accumulation curve and the estimated curve. Curve-fitting predictions of species accumulation assume that species are randomly distributed, but if sponges contain only a single shrimp species more often then expected, as shown in Fig. 6, observed accumulation of species should occur more slowly than expected, which Fig. 2(a) demonstrates. However, non-random sampling of sponges could also contribute to a lower than expected accumulation curve. 

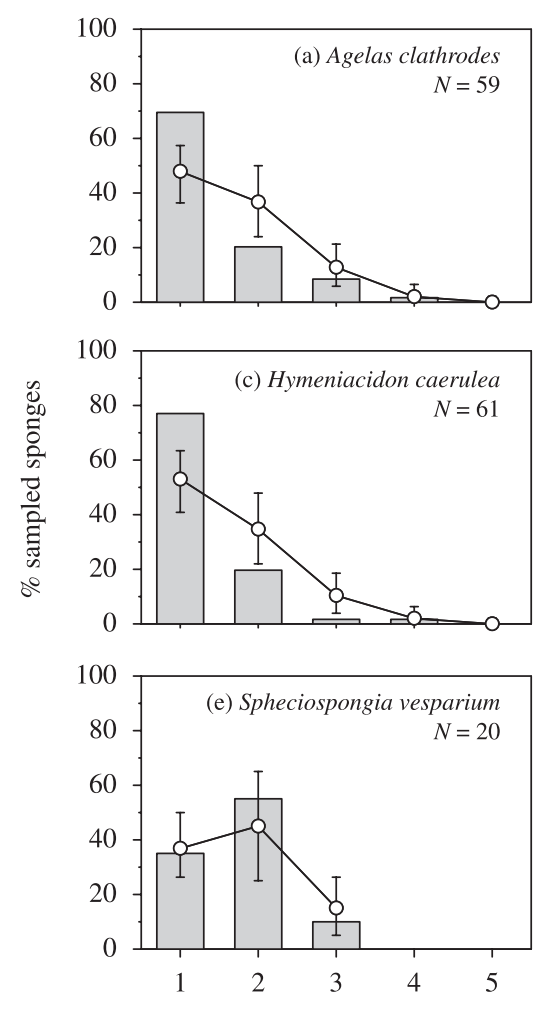

No. of shrimp species present
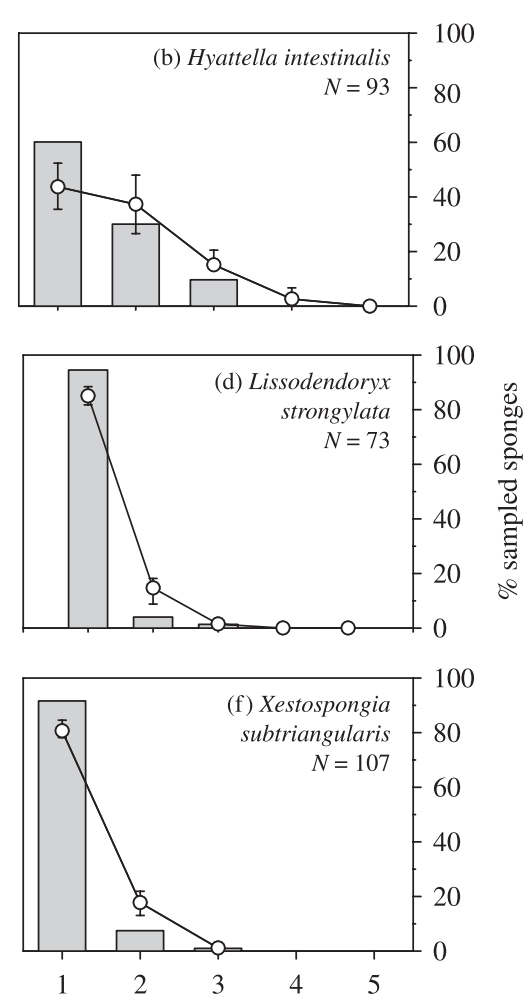

Figure 6 Patterns of co-occupancy by Synalpheus shrimp species sharing the same host species. Bars show the observed numbers of individual sponges inhabited by a particular number of shrimp species. Circles show the median $( \pm 95 \% \mathrm{CI})$ expected number of sponges inhabited under the assumption of random distribution of shrimp species occurrences among individual sponges (see text for calculations).
The host-use patterns we found can be compared with the previously most comprehensive data set on sponge-dwelling shrimp host-use patterns (Dardeau, 1984). In a survey of 13 sponge-dwelling Synalpheus species from the Florida Middle Ground, Gulf of Mexico, Dardeau (1984) found, as we did, that a majority (10 species) were each found in a single species of sponge. However, while Dardeau found only two shrimp species with a host range greater than one, we found 12 shrimp species (44\%) that each inhabited at least two sponge species, and three shrimp species inhabiting five or more sponge species. Additionally, all gambarelloides-group species found by Dardeau inhabited only one of two host species, A. dispar or S. vesparium. The remaining seven of Dardeau's shrimp-infested sponge species hosted only non-gambarelloides shrimp, most of which were classified as casual or accidental sponge associates. The contrasts between our data (Table 1) and those of Dardeau (1984) probably reflect both the higher diversity and the greater number of specimens of sponges collected in Belize than in the Gulf of Mexico.

Our study appears unusual in sampling a wide diversity of discrete habitat units (sponges), distinguishing it from several other studies of coral reef cryptic biodiversity. Previous studies focusing on motile cryptofauna usually either collected a limited number of samples from a single discrete habitat (i.e. individual coral heads of a single species: Lewis \& Snelgrove, 1990; MorenoForero et al., 1998), or were not identified to the species or even generic level (Klumpp et al., 1988; Preston \& Doherty, 1994). Regardless, rough comparisons can be made between our results and those of others. Hotchkiss (1982) collected ophiuroids from reefs in the vicinity of $\mathrm{CBC}$. Brittle stars are very abundant on the reef, and reflect a similar diversity, with 36 species found, albeit in 16 genera and 11 families. Ochoa-Rivera et al. (2000) sampled coral rubble from Cozumel, Mexico, focusing on the polychaete cryptofauna. They recovered 42 worm species from 36 genera and 19 families, not substantially more than the 32 species of Synalpheus found in our similar quantitative rubble samples. However, the results of the study of Ochoa-Rivera et al. (2000) differ from those of many other studies of cryptofaunal communities (reviewed in Hutchings, 1983), which usually found that polychaetes were far and away the most diverse group found on the reef, albeit not within a single genus. Kohn's classic studies $(1967,1990,2001)$ on the Indo-Pacific gastropod Conus, the most diverse genus of marine invertebrate, resulted in species counts ranging from 20 to 32 for single reefs. These species richness values are comparable to ours, even though the Indo-Pacific is considered to be the centre of diversity for both Conus and Synalpheus, and we focused on sampling only a single subgroup of Synalpheus. While some cryptofauna studies showed Synalpheus species to be less common and diverse than many other invertebrates (Abele, 1976; Lewis \& Snelgrove, 1990; Moreno-Forero et al., 1998), few mentioned the presence of sponge samples in their collections, and the few Synalpheus found were predominantly non-sponge dwelling species. Thus, overall, our results suggest that Synalpheus shrimp are among the most diverse invertebrates on coral reefs.

Differences in host-use patterns among habitats could be tested for two sponges that were commonly collected in both deep and shallow reefs. Shallow-water A. clathrodes harboured three shrimp species, two of which were specialists in Agelas species, whereas specimens of this sponge from deeper water 
Figure 7 Number of individual shrimp inhabiting a sponge (an estimate of sponge size) plotted against the number of shrimp species co-inhabiting that particular sponge, for each sponge species, of which 50 or more individuals were sampled.
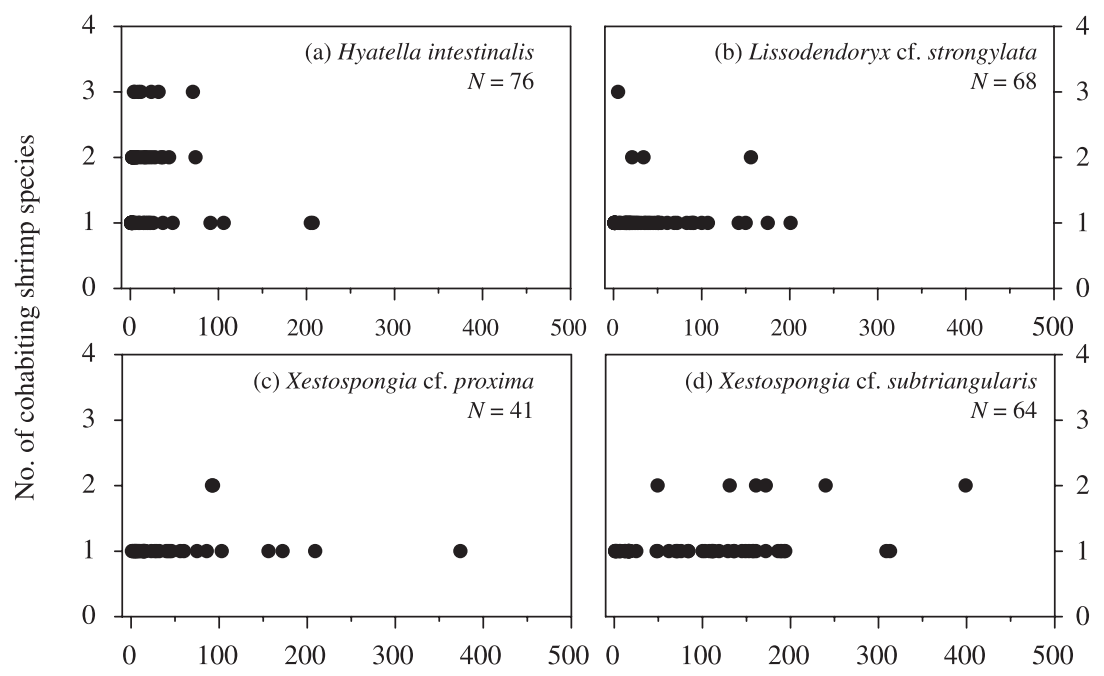

No. of cohabiting individuals
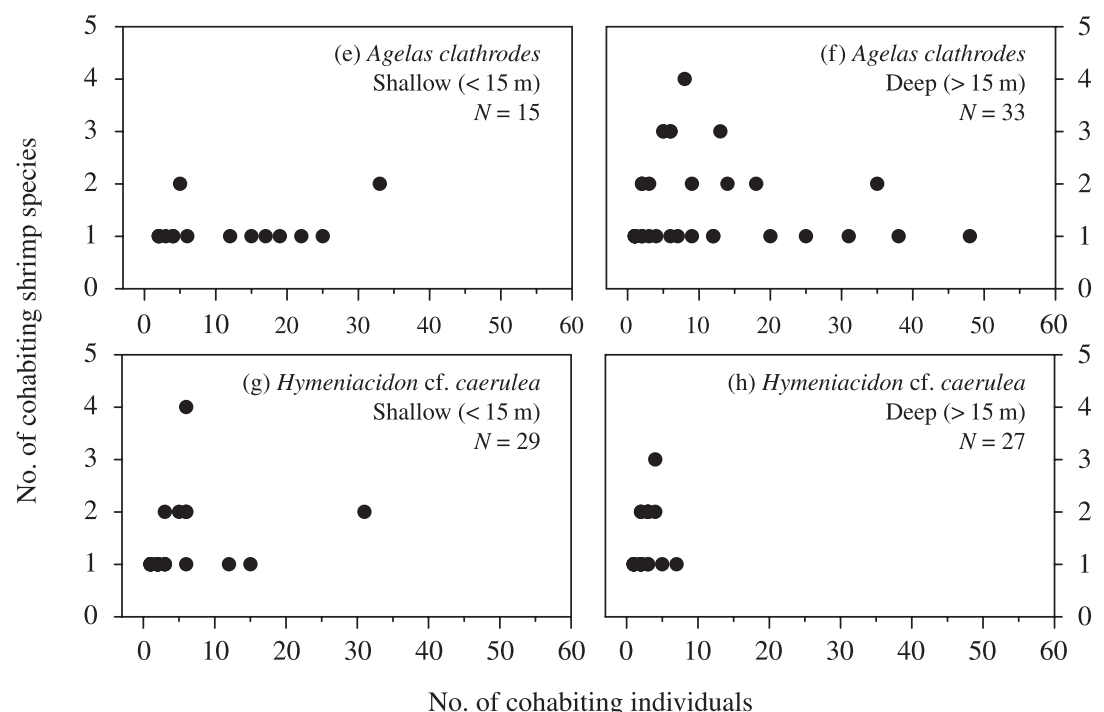

No. of cohabiting individuals harboured six shrimp species, including two additional specialists on Agelas; the shallow-water species were a subset of the deepwater species. Consequently, Shannon-Wiener species diversity was much greater in deep than in shallow A. clathrodes. While we collected almost twice as many deep than shallow water $A$. clathrodes, we reached the total diversity of both by the 10th collected sponge, suggesting that this diversity difference is real. In addition, frequency of habitation differed for the species that were found in both shallow and deep sponges. Synalpheus chacei was more common in A. clathrodes from shallow (73\% of specimens) than deep (39\%) water. This may in part be due to the dearth of alternate hosts $(H$. intestinalis and $L$. cf. strongylata) in shallow water compared to deep water. Conversely, the other two common inhabitants (Synalpheus agelas and S. 'bousfieldi A'), both Agelas specialists, were more frequently found in deep (34\% and $31 \%$, respectively) than in shallow sponges ( $4 \%$ and $22 \%$, respectively). Whether the more frequent presence of $S$. chacei in shallow sponges might have reduced the occurrences of the other two species, or vice versa, is unknown.
A second sponge species, $H$. cf. caerulea, was collected in about equal numbers from deep and shallow waters (Table 1). While the number of shrimp species inhabiting $H$. cf. caerulea was similar between depths, Shannon-Wiener diversity was substantially higher in deep than in shallow samples, mirroring the pattern found in A. clathrodes. Interestingly, almost twice as many individual shrimp were found inhabiting the shallow sponges than the deep, but this was due to the presence of three colonies (totalling 56 individuals) of the eusocial species $S$. 'rathbunae A', found only in shallow $H$. cf. caerulea.

What drives patterns of Synalpheus occupancy of sponges? One fundamental aspect is sponge morphology. For example, shrimp obviously cannot occupy sponges without suitable canal spaces, nor can large shrimp fit in sponges with small internal canals. But Duffy (1992) demonstrated experimentally that space occupation also involves choice, as two species of Synalpheus cooccurring in the same sponge in Panama segregated themselves according to canal width. However, whether overall patterns of co-occupancy are controlled by heterogeneity in sponge canal 
size is unknown. A second important factor supported indirectly by our data is competition. The primary competitors for space in sponges are likely to be other species of Synalpheus (Dardeau, 1984; Duffy, 1996c,d, 2003). One indirect approach to estimating strength of competition is to ask whether species co-occur more or less frequently than would be expected by chance. When we randomized shrimp species occurrences in individual sponges to test this, shrimp species were found alone in individual sponges significantly more often than expected for five of six sponge species, and for most sponge species, significantly fewer individual sponges contained two coexisting shrimp species than would be expected (Fig. 6). This suggests that shrimp actively avoid or exclude congeners. Moreover, the patterns of shrimp distribution we found are consistent with the hypothesis (Duffy et al., 2000) that eusociality provides sponge-dwelling shrimp with a competitive advantage. Most of the sponge species we sampled were dominated, in terms of both numbers of individuals and frequency of occurrence, by a few shrimp species, and most of these were eusocial species (S. chacei, S. regalis, S. filidigitis, and S. 'rathbunae A'). These social shrimp not only often dominated the sponges they inhabited (Fig. 4), as shown previously (Duffy et al., 2000), they commonly inhabited a larger number of sponge species than did non-eusocial shrimp. In contrast, the few noneusocial shrimp that consistently inhabited a particular sponge species, such as S. agelas Pequegnat and Heard, 1979, S. 'bousfieldi A', S. 'brevicarpus orange', and S. 'pandionis giant', tended to be host specialists, and were usually present at low densities within a sponge. The eusocial S. chacei (Duffy, 1998) might be considered the most successful sponge-dwelling Synalpheus species on the Belizean Barrier Reef, in that it was found in at least half the samples of each of four different sponge species. The eusocial S. filidigitis was found in at least half the specimens of each of two sponge species. No other shrimp occupied over half the specimens of more than a single sponge species.

Our quantitative collections confirm that dominance of individual sponges by social shrimp also extends to the level of the whole community in coral rubble environments. To obtain an unbiased estimate of relative abundance of shrimp species on shallow reefs, we quantified shrimp abundance in rubble samples from the Sand Bores, in which sponges were common but cryptic, and thus had little influence on sample collection. Consistent with the dominance of eusocial species within individual sponges just described, these quantitative samples were also strongly dominated by social species (Fig. 5), with almost 70\% of shrimp, on average, coming from the four eusocial species. Thus, the strong numerical dominance (Figs $4 \& 5$ ) and greater average host range (Fig. 3a) of eusocial species suggest that eusociality confers a strong advantage in competing for the host resource, and support earlier evidence for competitive superiority of social species from shrimp distributions (Duffy et al., 2000) and behavioural experiments (Toth \& Duffy, 2005). These patterns show interesting parallels to those for social insects on land, where eusocial ants, termites, and bees strongly dominate terrestrial insect assemblages and have profound impacts on terrestrial ecosystem processes (Wilson, 1990). Nevertheless, it should be emphasized that our study focused specifically on, and applies primarily to, sponges as habitats. and while sponges are a significant component of most Caribbean coral reefs, with surface area coverage of up to $24 \%$ in open reef habitats, and sometimes over $50 \%$ in cryptic rubble habitat (Diaz \& Rützler, 2001), there are of course wide areas of tropical shallow-water habitats with little or no sponge cover that presumably harbour other non-social alpheids. Although, in our experience, density of alpheids is low in such habitats, it is possible that such pair-living alpheids are more abundant than social species at the level of entire landscapes.

This survey has significantly increased our understanding of the species diversity of sponge-dwelling Synalpheus shrimp in the Caribbean, the host-use patterns associated with this diverse group, and the potential role of their unique eusocial lifestyle in contributing to these patterns. We found that shrimp species richness is considerably higher, and host specificity narrower, than previously known, that species co-occur less frequently than expected, suggesting competitive exclusion, and that eusocial species dominate the fauna numerically, and tend to have wide host ranges. These patterns support the conclusion that diversity of cryptic coral-reef organisms is considerably higher than presently recognized and that this diversity is fostered in part by specific symbiotic and competitive interactions among reef organisms.

\section{ACKNOWLEDGEMENTS}

We are grateful to Klaus Ruetzler, Mike Carpenter, the late Brian Kensley, and the staff of the Pelican Beach Resort for facilitating our research at Carrie Bow Cay over the years, and to the National Science foundation (DEB-9201566, DEB-9815785, IBN-0131931), the Smithsonian Institution (Postdoctoral Fellowship), and the Smithsonian Institution's Caribbean Coral Reef Ecosystems (CCRE) program for long-term support of this research. For assistance in the field, we are grateful to James Douglass, Geoff Keel, Monica Lara, Cheryl Morrison, Michelle Nestlerode, Paul Renaud, and Eva Tóth. We would like to thank Brian Silliman, Sammy De Grave, and anonymous reviewer for comments and suggestions that strengthened this manuscript. We also thank Mark Siddall for discussion and for assistance with the curve-fitting analyses. This is VIMS contribution no. 2707 and CCRE contribution no. 737.

\section{REFERENCES}

Abele, L.G. (1976) Comparative species composition and relative abundance of decapod crustaceans in marine habitats of Panama. Marine Biology, 38, 263-278.

Adey, W.H. (1977) Shallow water Holocene bioherms of the Caribbean Sea and West Indies. Proceedings, 3rd International Coral Reef Symposium (ed. by D.L. Taylor), pp. 21-24. Rosenstiel School of Marine and Atmospheric Science, Miami, Florida, USA.

Banner, D.M. \& Banner, A.H. (1975) The alpheid shrimp of Australia. Part 2: The genus Synalpheus. Records of the Australian Museum, 29, 267-389. 
Blank, S., Seiter, C. \& Bruce, P. (2001) Resampling stats for Excel, Version 2.0. Resampling Stats Inc., Arlington, Virginia, USA.

Burnham, K.P. \& Overton, W.S. (1978) Estimation of the size of a closed population when capture probabilities vary among animals. Biometrika, 65, 625-633.

Chace, F.A. (1972) The shrimps of the Smithsonian-Bredin Caribbean expeditions with a summary of the West Indian shallow-water species (Crustacea: Decapoda: Natantia). Smithsonian Contributions to Zoology, 98, 1-179.

Chace, F.A. (1988) The caridean shrimps (Crustacea: Decapoda) of the Albatross Philippine Expedition, 1907-10, Part 5: Family Alpheidae. Smithsonian Contributions to Zoology, 466, 1-99.

Chao, A. (1987) Estimating the population size for capturerecapture data with unequal catchability. Biometrics, 43, 783-791.

Choat, J.H. \& Bellwood, D.R. (1992) Reef fishes: their history and evolution. The ecology of fishes on coral reefs (ed. by P.F. Sale), pp. 39-66. Academic Press, New York.

Coutière, H. (1908) Sur les Synalphées americaines. Comptes Rendus Hebdomadaires des Séances de l'Académie de Sciences, 146, 710-712.

Coutière, H. (1909) The American species of snapping shrimps of the genus Synalpheus. Proceedings of the United States National Museum, 36, 1-93.

Dardeau, M.R. (1984) Synalpheus shrimps (Crustacea: Decapoda: Alpheidae). I. The gambarelloides group, with a description of a new species. Memoirs of the Hourglass Cruises, 72, 1-125.

Diaz, M.C. \& Rützler, K. (2001) Sponges: an essential component of Caribbean coral reefs. Bulletin of Marine Science, 69, $535-546$.

Dobkin, S. (1965) The first post-embryonic stage of Synalpheus brooksi Coutière. Bulletin of Marine Science, 15, 450-462.

Dobkin, S. (1969) Abbreviated larval development in caridean shrimps and its significance in the artificial culture of these animals. FAO Fisheries Report, 57, 935-946.

Duffy, J.E. (1992) Host use patterns and demography in a guild of tropical sponge-dwelling shrimp. Marine Ecology Progress Series, 90, 127-138.

Duffy, J.E. (1996a) Eusociality in a coral-reef shrimp. Nature, 381, 512-514.

Duffy, J.E. (1996b) Resource-associated population subdivision in a symbiotic coral-reef shrimp. Evolution, 501, 360-373.

Duffy, J.E. (1996c) Species boundaries, specialization, and the radiation of sponge-dwelling alpheid shrimp. Biological Journal of the Linnean Society, 58, 307-324.

Duffy, J.E. (1996d) Synalpheus regalis, new species, a spongedwelling shrimp from the Belize Barrier Reef, with comments on host specificity in Synalpheus. Journal of Crustacean Biology, 163, 564-573.

Duffy, J.E. (1998) On the frequency of eusociality in snapping shrimps (Decapoda: Alpheidae), with description of a second eusocial species. Bulletin of Marine Science, 623, 387-400.

Duffy, J.E. (2003) The ecology and evolution of eusociality in sponge-dwelling shrimp. Genes, behavior, and evolution in social insects (ed. by T. Kikuchi), pp. 1-38. University of Hokkaiko Press, Sapporo, Japan.

Duffy, J.E., Morrison, C.L. \& Rios, R. (2000) Multiple origins of eusociality among sponge-dwelling shrimps Synalpheus. Evolution, 542, 503-516.

Felder, D.L. \& Chaney, A.H. (1979) Decapod crustacean fauna of Seven and One-Half Fathom Reef, Texas: species composition, abundance, and species diversity. Contributions in Marine Science, 22, 1-29.

Hotchkiss, F.H. (1982) Ophiuroidea (Echinodermata) from Carrie Bow Cay, Belize. The Atlantic Barrier Reef ecosystem at Carrie Bow Cay, Belize, 1: structure and communities (ed. by K. Rützler and I.G. Macintyre), pp. 387-412. Smithsonian Institution Press, Washington DC, USA.

Hutchings, P. (1983) Cryptofaunal communities of coral reefs. Perspectives on coral reefs (ed. by D.J. Barnes), pp. 200-208. Australian Institute of Marine Science, Manuka, ACT, Australia.

Kensley, B. (1998) Estimates of species diversity of free-living marine isopod crustaceans on coral reefs. Coral Reefs, 17, 8388.

Klumpp, D.W., McKinnon, A.D. \& Mundy, C.N. (1988) Motile cryptofauna of a coral reef: abundance, distribution and trophic potential. Marine Ecology Progress Series, 45, 95-108.

Knowlton, N. \& Jackson, J.B.C. (1994) New taxonomy and niche partitioning on coral reefs: jack of all trades or master of some? Trends in Ecology and Evolution, 9, 7-9.

Kohn, A.J. (1967) Environmental complexity and species diversity in the gastropod genus Conus on Indo-West Pacific reef platforms. American Naturalist, 101, 251-259.

Kohn, A.J. (1968) Microhabitats, abundance and food of Conus on atoll reefs in the Maldive and Chagos Islands. Ecology, 49, 1046-1061.

Kohn, A.J. (1990) Tempo and mode of evolution in Conidae. Malacologia, 32, 55-67.

Kohn, A.J. (1997) Why are coral reef communities so diverse? Marine biodiversity. Patterns and processes (ed. by R.F.G. Ormond, J. Gage and M. Angel), pp. 201-215. Cambridge University Press, New York, USA.

Kohn, A.J. (2001) Maximal species richness in Conus: diversity, diet and habitat on reefs of northeast Papua New Guinea. Coral Reefs, 20, 25-38.

Lewis, J.B. \& Snelgrove, P.V.R. (1990) Corallum morphology and composition of crustacean crytpofauna of the hermatypic coral Madracis mirabilis. Marine Biology, 106, 267-272.

Michaelis, M. \& Menten, M.L. (1913) Der kinetic der invertinwirkung. Biochemische Zeitschrift, 49, 333-369.

Moreno-Forero, S.K., Navas, S., G.R. \& Solano, O.D. (1998) Cryptobiota associated to dead Acropora palmate (Scleractinia: Acroporidae) coral, Isla Grande, columbian Caribbean. Revista de Biologia Tropical, 46, 229-236.

Morrison, C.L. Rios, R. \& Duffy, J.E. (2004) Phylogenetic evidence for an ancient rapid radiation of Caribbean sponge-dwelling snapping shrimps (Synalpheus). Molecular Phylogenetics and Evolution, 30, 563-581.

Ochoa-Rivera, V. Granados-Barba, A. \& Solis-Weiss, V. (2000) The polychaete cryptofauna from Cozumel Island, Mexican Caribbean. Bulletin of Marine Science, 67, 137-146.

Ormond, R.F.G. Roberts. (1997) The biodiversity of coral reef fishes. Marine biodiversity. Patterns and processes (ed. by R.F.G. 
Ormond, J. Gage and M. Angel), pp. 216-257. Cambridge University Press, New York, USA.

Preston, N.P. \& Doherty, P.J. (1994) Cross-shelf patterns in the community structure of coral-dwelling Crustacea in the central region of the Great Barrier Reef. II. Cryptofauna. Marine Ecology Progress Series, 104, 27-38.

Reaka-Kudla, M.L. (1997) The global biodiversity of coral reefs: a comparison with rain forests. Biodiversity II. Understanding and protecting our biological resources (ed. by M.L. Reaka-Kudla, D.E. Wilson and E.O. Wilson), pp. 83-108. Joseph Henry Press, Washington DC, USA.

Reed, J.K., Gore, R.H., Scotto, L.E. \& Wilson, K.A. (1982) Community composition, structure, areal and trophic relationships of decapods with shallow- and deep-water Oculina varicose coral reefs. Studies on decapod Crustacea from the Indian River Region of Florida, XXIV. Bulletin of Marine Science, 32, 761-786.

Ríos, R. (2003) Synalpheus shrimp from Carrie Bow Cay, Belize. Systematics, phylogenetics and biologial observations (Crustacea: Decapoda: Alpheidae). Dissertation. Virginia Institute of Marine Science/School of Marine Science. The College of William and Mary, Williamsburg, Virginia, USA.
Ríos, R. \& Duffy, J.E. (1999) Description of Synalpheus williamsi, a new species of sponge-dwelling shrimp (Crustaceana: Decapoda: Alpheidae), with remarks on its first larval stage. Proceedings of the Biological Society of Washington, 112, 541552.

Rützler, K. \& Macintyre, I.G. (1982) The habitat distribution and community structure of the barrier reef complex at Carrie Bow Cay, Belize. The Atlantic Barrier Reef ecosystem at Carrie Bow Cay, Belize, I: Structure and communities (ed. by K. Rützler and I.G. Macintyre), pp. 9-45. Smithsonian Institution Press, Washington DC, USA.

Smith, E.P. \& van Belle, G. (1984) Nonparamtetric estimation of species richness. Biometrics, 40, 119-129.

Snelgrove, P.V.R. \& Lewis, J.B. (1989) Response of a coral-associated crustacean community to eutrophication. Marine Biology, 101B, 249-257.

Toth, E. \& Duffy, J.E. (2005) Coordinated group response to nest intruders in social shrimp. Biology Letters, In press. (doi: 10.1098/rsbl.2004.0237).

Wilson, E.O. (1990) Success and dominance in ecosystems: The case of the social insects. Ecology Institute, Oldendorf/Luhe, Germany. 